Murmurations:

Journal of

Transformative

Systemic

Practice

\title{
Towards Safe(R) Uncertainty: an Offering for Managers and Supervisors during a Pandemic
}

\author{
Jennifer McKinney
}

\section{Volume 3}

Issue 1

Autumn 2020

Keywords:

safe uncertainty,

supervision, management, useful questions, COVID-19, pandemic

Citation Link

\section{Abstract}

In this paper I use Barry Mason's safe uncertainty framework to assist supervisors and/or managers to enable staff to navigate their way through difficulties and dilemmas within the context of the current COVID-19 pandemic. From a position that safety cannot be guaranteed, only worked towards, I use the idea of safe(R) uncertainty, R representing ideas such as reflexivity, resources, restraints and relational thinking to open up conversations within the supervisory process. Examples of supervision are provided to illustrate how the framework can provide a space for curiosity and the co-construction of possibilities for movement when staff come to an impasse. Examples of questions are provided that may help in the process. My intent is to free up some space for thinking about these processes rather than provide some type of prescriptive practice.

"The only thing that makes life possible is permanent, intolerable uncertainty: not knowing what comes next."

- Ursula K. Le Guin 1969, The

Left Hand of Darkness

\section{Introduction}

Fingers poised above the keyboard of my laptop, I become aware of my own nagging uncertainty about writing this article. I lower my hands, resting my wrists on the edge of the desk, thinking about what I am trying to achieve, why I am driven to think about this concept, struck by the evolving process the writing of this article has undergone over time before reaching its current format. Responding to this visceral uncertainty I see that writing about it is a process, the development of a relationship with those who read it, a space where hopefully their ideas will unfold and evolve. It feels important therefore to convey to the reader that this article 
is not intended to take a certain stance on how uncertainty should be thought about or carried out in conversations with one another. It is not an attempt to find one definition for uncertainty nor to give a historical explanation of the subject, nor is it intended to provide definitive answers or a prescriptive practice. Instead I offer some of my own unfinished thoughts on the idea based on my current epistemological position.

I extend an invitation to the reader to think more about the subject and its potential for opening possibilities for communicating more effectively when managing and/or supervising staff during the COVID-19 pandemic. In an already complex world, the onset of the COVID-19 pandemic has introduced new ways of relating, maintaining a social distance, wearing Personal Protective Equipment (PPE), communicating more via social media to name a few. As highlighted by the Murmurations Writing Project (2020) we have entered a time of systemic flux. Uncertainty can also be viewed as a liminal site, and as the above Le Guin (1969) quote suggests is not necessarily a negative experience but can be a place of creativity and opportunity. Nora Bateson (2016) explores both sides of the coin, arguing that while uncertainty can bring a useful approach to the complexity of peoples' lives, the concept can lead to polarities of approaches, from the arrogant statement of beliefs to an unclear woolly thinking.

When used in an exploratory way, the concept enables us to inquire about the complexities of people's lives, not trying to understand too quickly (Anderson \& Goolishian 1988) or impose our perceived solutions onto others. Considering such unprecedented times as these where COVID-19 has had personal and professional relational consequences, different ways of responding to issues presented to us are now required (ibid). This paper focuses on supervisors and managers and how they can consider Mason's safe uncertainty framework $(1993,2019)$ to respond to staff in ways that help navigate the unchartered territory of COVID-19. I have used the framework in both frontline and private practice and from my point of view it is applicable to any managers or supervisors dealing with challenges. Some examples of work are provided with details changed so that persons cannot be identified.

\section{An Evolving Interest in Uncertainty}

As I began writing I sat on the banks of the River Roe where the passing water provided a metaphor for the flow of ever-changing life. I had sought out this place as somewhere calming and peaceful to begin to bring my thoughts together. This river is situated in the North West of Northern Ireland where I currently live and work as a systemic and family psychotherapist, social worker, clinical lecturer, and doctoral candidate. As a White, middle aged, woman who cannot be fully dislodged from her working class roots, born during the civil rights movement here, I was acutely aware of the uncertainties and complexity that accompanied life in a way that the polarity of views often did not convey. As I gained life experience it became apparent that uncertainty is a way of being, a part of everyday life no matter where one lives. As life flows it is shaped by uncertainty, movement, change. For some, uncertainty is greater than for others dependent on gender, race, ability, class, religion, sexual orientation etc. COVID-19 has highlighted such inequalities in that people from Black and Ethnic minority backgrounds, people from working class backgrounds, men and people with pre-existing conditions are all thought to be more vulnerable to the disease. The tragic and unnecessary deaths of George Floyd and Brionna Taylor highlighted the abuse of power and privilege and the Black Lives Matter movement emerged. 
Questions are raised about where power lies, which voices are privileged and socio-economic inequalities that impact daily on people's lives. Systemic psychotherapy has sought to take account of these and similar themes through the development of the "Social GGRRAAACCEEESSS" (Burnham 1992; 1993; 2012; Roper-Hal 1998), one of its aims being to promote cultural competence in working with individuals and families.

In a very different context, I wondered about the potential these questions would hold if they were also offered to staff within frontline services. Are workers able to find their voices? Are they silenced through for example a fear of showing vulnerability? Do we know how to talk about staff dilemmas and challenges while holding the "Social GGRRAAACCEEESSS" in mind? As a systemic psychotherapist these have become so important when talking about power and difference.

While these are my personal reasons for an interest in the subject area, uncertainty is an area that has been pondered and debated within many disciplines for many centuries. The concept has perplexed and preoccupied philosophers such as Socrates, Kierkegaard, Kant, and Wittgenstein (1969). Poets have eloquently expressed its place in their lives. For example, Rankine's (2004) meditation on life following 9/11 and Whitman's realisation that "I have not really understood any thing, not a single object, and that no (hu)man ever can" (Murphy 2004). Scientists have also explored the subject culminating in works such as Heisenberg's Uncertainty Principle in quantum physics. Art such as de Chirico's 1913 painting The Uncertainty of the Poet have visually expressed it.

This article's origins began as a conversation with clinical psychology colleagues about the organisational need to support frontline managers to support their staff during the COVID-19 pandemic. This included social workers, doctors, nurses, and social care staff. Reflecting on this I considered various conversations I was part of with social care staff which highlighted the polytheistic nature of experiences of the pandemic. A range of emotions were described by them including tentativeness, fear, ambivalence, anxiety, doubt, and creativity. While some staff had expressed concern about the ability to carry out their duties and provide safety for others, some had welcomed the slowing down of work, others welcomed new ideas such as working online and from home, some were struggling with becoming teachers to their children, others were anxious about their families and how they could keep them safe while they were out working in the frontline. Statements provided clues to certain and uncertain positions taken: "I'm worried that I will pass something on to my elderly parents". "It's just about good hygiene". "I'm afraid to go into people's houses". "A mountain is being made out of a molehill". It occurred to me that in some ways systems were generating tensions in their interfaces with each other in the COVID-19 context. The government were making regular changes to their thinking and/or not giving direction, organisations were trying to carry out their work differently. Staff were impacted both in their personal and professional lives. Yet the personal, professional, and social worlds were often not interacting well together culminating in the growth of uncertainty during the pandemic and sometimes getting in the way of being able to think about families. A potential consequence of this is that, to use the words of Yeats, "the centre cannot hold" (1994).

With these thoughts at the forefront of my mind I suggested to my colleagues that Mason's safe uncertainty framework $(1993,2019)$ could be useful as a compass to help managers enable staff to navigate their way through dilemmas and struggles during the pandemic (Figure 1). As Mason describes it, the framework "is particularly associated with addressing risk factors and how it can 
contribute to the development and maintenance of safer relationships" $(2019$, p. 343). In taking a relational stance towards uncertainty Mason's framework takes the form of a quadrant with four domains: safe certainty, unsafe certainty, unsafe uncertainty, and safe uncertainty. My idea was that using this framework could help move staff from positions of impasse, fear and anxiety towards a more favoured position of safe uncertainty, which Mason (2019) describes as "always evolving...a place where doubt, uncertainty, unhelpful difference, can be safely, if at times uncomfortably, explored as part of developing and maintaining emotional intimacy and more constructive, safer relationships" (ibid, p. 347). It provides the opportunity to open up conversations with staff, to hear multiple perspectives, develop healthy working relationships and for something different to be created within those relationships, a space for multiplicity, connectivity and becoming (Deleuze \& Guattari 1980).

Listening to these ideas, my psychology colleagues invited me to create a guide that would help managers in their day to day work. While I enthusiastically took on this task, during the process I became acutely aware that guides in their general approach tend to leave no room for invitations to think. are written with a sense of certainty, from a position of knowing, and questions are rarely asked about the writer's own personal and theoretical biases. And so, this paper came about through an attempt to immerse myself in the process and to connect with the reader in a way that did not feel possible through providing an organisational guide.

\section{From Safe Uncertainty to Safe(R) Uncertainty}

Mason defines safe uncertainty as a position that "is never fixed. It is always evolving. It is a place where doubt, uncertainty, unhelpful difference, can be safely, if at times uncomfortably, explored as part of developing and maintaining emotional intimacy and more constructive, safer relationships" (2019, p. 347) comprising elements of curiosity (Cecchin 1987), experimenting with difference, taking relational risks, holding a position of authoritative doubt, a willingness to work with family of origin scripts and developing a culture of contribution. Mason's work has been invaluable to the systemic field and his development of safe uncertainty has enabled a strengthening of practice where risk, doubt and uncertainty are concerned.

I took a slightly different position on the safe uncertainty domain. The more of living I experience, the more I practise, leads me to believe that safety is never guaranteed, only ever worked towards, sought out. In taking this stance, I make use of the term safe(R) uncertainty. This prevents me from getting too comfortable and reminds me of the complexity of life. It prevents me from trying to rush too quickly to fix or solve. It is a space for me to explore, think, question, learn and try to stay curious as well as trying not to become too complacent. In this quadrant I, and the managers and supervisors I have in mind, can be most helpful to those around us. 


\section{Safe}

SAFE CERTAINTY

SAFE UNCERTAINTY

Certainty

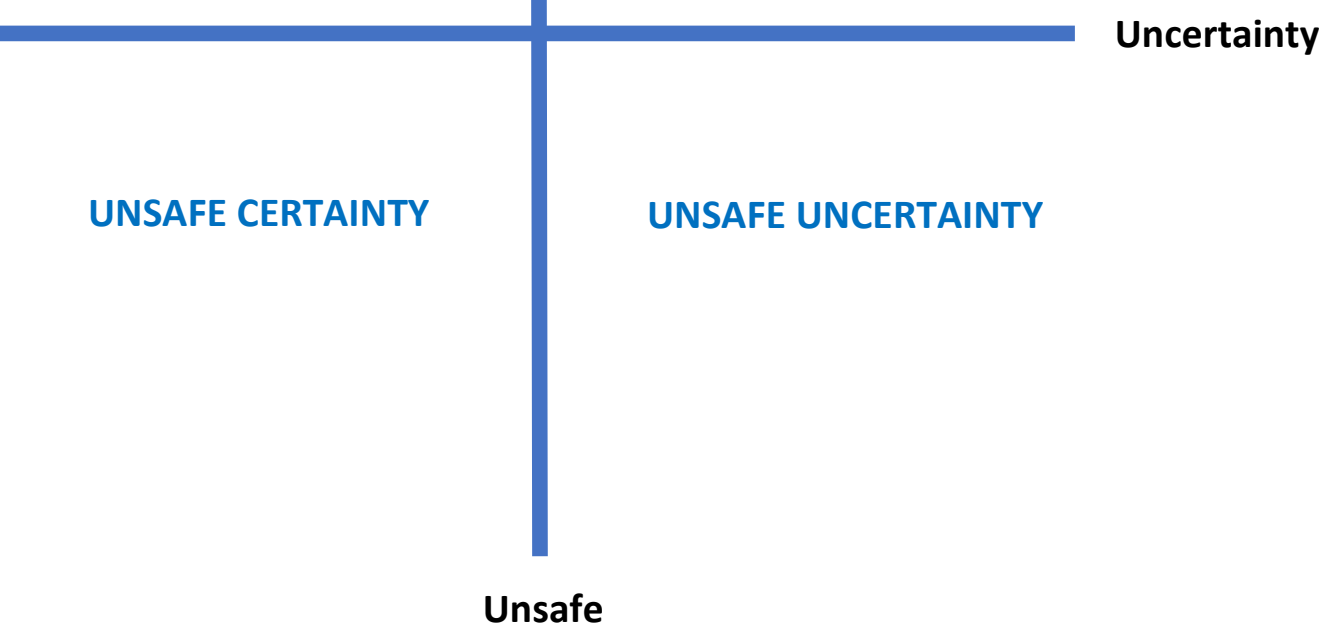

Figure 1. The Safe Uncertainty Framework (Mason 1993, 2019)

\section{The R number or "a number of Rs"}

The use of the bracketed $R$ in safe(R) uncertainty gained a greater meaning for me. In pandemics, the reproduction number $(R)$ is "the average number of secondary infections produced by a single infected person. An R number of 1 means that on average every person who is infected will infect 1 other person, meaning the total number of infections is stable. If $R$ is 2 , on average, each infected person infects 2 more people" (UK Govt 2020). The emphasis on this has created a sense of fear and uncertainty globally and at the same time, it has helped people to find ways of trying to create greater safety, demonstrating its limitations and benefits. Locating this idea within the very different context of safe uncertainty, managers and supervisors can help practitioners find ways to manage doubts and fears. Taking a compassionate, curious stance opens opportunities for the spirit of inquiry to become contagious, providing a context where different possibilities can emerge. From my perspective, there are several Rs within systemic thinking and beyond that enable me to use Mason's framework in a way that introduces difference and I situate these within the safe uncertainty quadrant. The more I pay attention to and use these Rs the safe $(R)$ my exploration of difficulties becomes. My hope is that holding these conversations will prove infectious to others who could then open up conversations and enable staff to shift their positions. 
The bracketed $\mathrm{R}$ could have meaning in relation to the following areas:

- Reflexivity

- Restraints

- Resources

- Relational thinking

\section{Reflexivity}

"Reflexivity is a stance we take towards the patterns we are co-creating when we communicate as well as being a set of practical skills and abilities that we can use" (Hedges 2010, p. 3) and Mason (2019) recognises the need for reflexivity to be central within his framework. It involves the ability to reflect-in-action (to think in the moment about our positions and actions and to reposition ourselves as necessary) and reflection-on-action (to think about our actions after the activity and to think about what went well and what we could have done differently) (Schön 1983). Extending this further Burnham (2005) refers to relational reflexivity as "initiating, responding to, and developing opportunities to consider, explore, experiment with and elaborate the ways in which they relate" (p. 4) while Krause (2012) defines comprehensive reflexivity as encompassing "recursiveness between the different aspects of meaning, interpretation, and experience held or expressed by persons (either clients or therapists) as well as the self-reflexivity of both the therapist and clients vis-à-vis their own history, development, and background and the contexts in which they participate" (p. 9).

These ideas are important because managers/supervisors, rather than request a case by case description of the staff member's work could be more helpful to their staff by being able to identify their own assumptions, by thinking about the particular context brought by the member of staff, and adjusting their actions to be more helpful to staff who may be struggling in their day to day work. This is particularly important during the pandemic as we are learning as we go along and will be actively experimenting with new ideas and new ways of working.

As a beginning to this process, just take a moment to consider the following short exercise:

Take a situation that you are uncertain about and imagine what could happen if it turns out ten times better than you hope it will. What emotions would you have attached to that experience? How would releasing those negative expectations free you? Have there been other times when you have felt uncertain about a situation and you were able to manage it effectively? What did you do that enabled you to manage this? Who supported you? What did you do then that you could apply to the issue now?

- Is there any new information emerging in your answers?

- What have you become more aware of now?

- How does focusing on possibilities and a more positive future leave you feeling?

- What one thing can you do differently to move the current issue forward?

Examine your perceived uncertainty. What lies at its root? What emotion comes up when you think about doing the thing that you are uncertain about?

- In comparison to the first exercise how does focusing on the problem leave you feeling? 


\section{Restraints}

Burnham's PPRR framework (Neden \& Burnham 2007) takes account of restraints and resources to open up conversations to negotiate different possibilities when working our way through problems or difficulties. In terms of restraints, practising the safe uncertainty framework gives permission to talk about difficult things. When I find myself stuck in an unhelpful position, I ask myself things such as "What is organising my thinking? What is getting in the way of finding possibilities? What are the assumptions I am bringing that is leading to this impasse? How can I respond differently to the situation?"

\section{Resources}

When things feel unsafe and/or uncertain there can be a tendency to focus on the negatives and thoughts and conversations can become quite problem saturated. This may often occur during times of stress and discomfort. An exploration of strengths and assets can help lead to imaginative ways forward when feeling stuck. This has the potential for imaginative thinking, developing goals and creating action plans that can help staff feel supported in our work. When trying to move from a problem saturated to a possibility charged position, I find questions helpful such as "What, from my past practise tells me that I am able to pass through barriers? What are the key strengths I have that I can use in this situation? What do other people notice about my strengths? When I have come across similar situations in the past, what has enabled me to work my way through them?"

\section{Relational thinking}

Shotter's (2012) ideas on "withness" and systemic thinking shine a light on the relational aspect of a shared phenomenon, in our case, the highly visible invisible COVID-19. His ideas also highlight important things to consider when relating to each other about our shared experiences.

It is a knowing what to do with one's participation within a situation, with one's 'place' within it, and with how one might 'go on' playing one's part within it - a knowing in which one is affected by one's surroundings...

Shotter 2012, p. 3

How can we play an active and useful part in moving forward given that we are interconnected not just with each other but with the world we inhabit? We can only actively experiment with ideas, holding the other in mind, being aware of our ethical intent, and collaboratively work through the situation with compassion and with care. We can play our part in empowering others to share those experiences. As already stated, the ideas in this paper are indeed just ideas, an opportunity to consider how we might have conversations or at least begin those conversations and how we might intra-act (Barad 2007) with each other and the systems within which we live and work. While potential questions have been provided to help such intra-actions there is the possibility that questions are only considered as a technique, without much thought. However, the thoughts that lie behind the questions are most important and we must focus on our intent (Tomm 1988).

Being introduced to a poem, attributed to Scottish psychiatrist R.D. Laing (Goleman 1985), by a mentor at University I have always tried to hold in mind that my intent goes hand in hand with the things I pay attention to, what I notice: 
The range of what we think and do is limited by what we fail to notice. And because we fail to notice that we fail to notice, there is little we can do to change; until we notice how failing to notice shapes our thoughts and deeds.

Goleman 1985, p. 24

This has always held a place for me in thinking about what is in the room. I ask myself questions following supervisory sessions such as: What were the things that stood out for me during that conversation? What did I notice about myself in the session? What did I notice about the supervisee? What am I noticing now that I did not attend to in the moment? What ideas did I foreground and background? What can I keep in mind to ask about next time? What is my relationship to this supervisory session? I also have a sense of the things I will never be able to notice because they are out of sight, invisible, they lie behind.

Shotter (2012) also discusses the importance of noticing. Using Shotter's words (ibid. p. 4), signified below via the use of italics, I place these different noticings, within the context of the COVID-19 pandemic, as these provide different lenses to view it from both personally and within our organisations:

Being struck by an event. With COVID-19 every single one of us has been impacted in one way or another, from having to change our practices, to changing how we relate to others, to being financially impacted, to not having treatment for an illness, to not being able to be with a sick loved one, to losing someone who is near and dear to us without the endings we would have liked. Asking questions such as How has COVID-19 impacted on you? What areas of your life have changed as a result of COVID19 ?

The sensing of a unique unitary whole. From my point of view there are two ways to explore this; as a sense of the self as a unitary whole, in other words a coherent sense of the self, and secondly seeing the self as a unitary whole within the world itself, feeling connected to our surroundings.

A disquiet at things not being quite right. This has emerged in many ways during COVID-19. There are feelings of fear for the self and others and a wondering about when or how we might emerge from this difficult time.

The coming into being of a type of public life that can strengthen solidarity, public freedom, a willingness to talk and to listen, mutual debate, and a commitment to rational persuasion. COVID-19 has taught us many things, e.g. to support each other, to collaborate, to appreciate the relationships that we have, to pay attention to ecological systems and the impact made on them. Within organisations this willingness to talk and listen is just as important.

What is not being said. We need to find dialogical ways to open up conversation and work with conflict in our lives. We can begin that within our working environments by taking "relational risks" (Mason 2005) with each other to try to begin to understand the other and to move towards a spirit of openness.

Telling moments when collective narratives begin to be revealed, e.g., when people begin to say "This is how we do things around here". Gathering these narratives is a starting point. This requires us to think about what has worked well, what has not worked, and what we can carry forward to improve our practices. 
Disquiets... a feeling that there is still a "something more "that has not yet been captured. I take the perspective that we can never know everything. We can only continue to learn. This means thinking about what lies behind and beyond what we see and things that we can never know. It feels that we are in a state of waiting at the minute. We are continuing to move through a process where other ideas will emerge that may change the future in a positive way.

When we as leaders are in dialogue with staff, these noticings are important to help us to think about the collective narratives we have, to consider what is not being said or the not yet said, to open up conversations and let difference emerge, and to not lose sense of the things that we have learned along the way.

\section{Unsafe Uncertainty}

Mason (2019) describes this position as "chaotic, paralysing, despairing, often a day-to-day existence emotionally and/or physically and/or financially...uncertainty about, and fear of, the future, not least the loss of how one hoped things would be" (p. 345). Whether we take this position and/or are positioned by others in this way, maintaining this position can feel paralysing for staff.

To give an example, during systemic supervision with a practitioner (I will refer to as Mary) I was struck by a change in her demeanour. A generally confident and conscientious worker she was not her usual energetic self. During our conversation Mary stated that she was not sure what to do anymore. She described feeling a bit frozen in her work. How could she carry out sessions online? "People need to be in the room" she said. How could she carry out some therapeutic work on the phone when some of her clients did not have access to the internet? I asked how this had left her feeling. "Powerless" she said. "I'm worried that I can't do it. I don't have the skills". I asked Mary would it be Ok if I talked to her a bit more about this and she agreed.

Mary was very open about her difficulties and did not need to be prompted much. For staff that find it difficult to voice their experiences there is the potential to open the conversation by asking questions such as the following:

- What would you like to talk about?

- Tell me what is going on for you at this point in time.

- What is your greatest worry at the moment?

- How long have you been thinking about this?

- What areas of work do you feel most stuck in?

- What are the resources that you bring with you that can help you to manage this?

- What can I, or other people. do to help you through this?

- What would you like to see happening that would help you to feel more confident in moving forward now? 
The conversation with Mary proceeded as follows:

Me: Have you ever felt like this before?

Mary: Never. Never in my personal life or in my work. I'm usually a strong person that can deal with anything. I just get on with it.

Me: So, this is a completely new feeling for you. (This question distinguishes Mary's feelings in this piece of work to other work she has carried out. What this does is emphasise that Mary does not have these difficulties all the time and helps to remind her that there are other times when she feels good about her work.) It sounds like it has been quite difficult. Yet even though you feel you are not able to do the therapy in a different way, you have persisted with it. (This amplifies Mary's commitment to the client even though it feels difficult and a further strength that Mary is willing to try different things to improve the therapeutic relationship.)

Mary: Yeeesss (uncertainly)

Me: And in those times that you have persisted has there been anything that has surprised you about yourself? (My intent is to enable Mary to identify her strengths and exceptions to her belief that she is not able to work well in this way).

Mary: (laughing) That I've even been able to use a computer like this. I'm not good with technology but I've managed it.

Me: So, you've learned a bit about technology. Great. Anything else that's surprised you?

Pause. Mary appears to be thinking hard. Then her eyes light up a little and she smiles. (Mary is thinking of real-life examples that enable her to have a different perspective on the issue. This is much more powerful than being told by me that she can do this work.)

Mary: Well there was this woman that I had seen a few times before lockdown happened. The sessions were hard. It was difficult for us to connect. She would be late for appointments or she would cancel. Since lockdown we have had three sessions online and I feel that things are going much better. (Mary is recognising her strengths/resources.)

Me: And what do you feel has been different?

Mary: I suppose thinking about it I was different. I took an interest in her home, admiring the clock behind her. She told me how that clock had been her mother's and how it reminded her of times with her mother before she had passed away.

Me: And how did you respond to that?

Mary: Well I wanted to hear more about her mother and her early experiences. She talked about times when she felt close to her and then times that were extremely difficult in her teenage years. We had conversations about time and how time changes relationships. It was wonderful. We explored her difficult relationships now.

Me: So, you were really interested and curious.

Mary: Yes, I look forward to the sessions now. I want to hear more about her experiences and how they relate to the here and now. I feel more relaxed now. 
Me: How come you hadn't felt relaxed before?

Mary: (pause) Thinking back I think I was concerned about my performance. This lady had been seen by many different people before and nothing seemed to help. I felt pressure that I had to be the one to help her but when I think about it this left me feeling very tense and I felt a bit useless, that I couldn't help her as a professional...

Me: And what effect did that have on her? (I want to connect Mary's response to the client's response, helping Mary to see the reciprocal process within the relationship.)

Mary: Oh, she seemed very tense too. Very wary of me.

Me: And what happened to your curiosity during that time?

Mary: (laughs again) Oh dear. I can see me sitting in the room and all I wanted to do was focus on the problem the referrer had given to me. I dived straight in. I thought I was being very professional.

Me: So, there was a real shift from before when you felt your curiosity had waned. (I want to draw out difference here between illustrating to Mary that her curiosity was not lost.) I'm really interested in your conversations with this woman about time and how it can change relationships and how your relationship to her has changed over time and in this time of having to do things in a different way. (I connect the theme of temporality and change that Mary brought up earlier in the conversation.) Thinking back to your earlier worries about carrying out therapy online, how would your relationship to online therapy need to change and what have you learned in your work with Clare that could help you with this?

Mary: I want to feel that I can connect to people, that I can bring a difference to people's lives, that they know I care. Thinking about Clare I need to pay attention and ensure my curiosity is not closed down by other people's stories about her and the problem.

Me: And how can you continue to do this?

Mary: I can use supervision in a different way. I can come with thoughts about why I might be stuck or struggling with a case. I can think of my beliefs and ideas that are getting in the way, things I've tried that don't work and I can come with an idea about how I think things need to change. Then my supervisor can help me to work out how I can get there.

Other questions that may have helped Mary to shift her position are:

- Have you successfully handled a similar situation before?

- If you changed your belief about this, what would be possible? What advice would you give someone else in a similar situation?

- What are some concrete steps you could take to achieve this goal?

- How might you turn these steps into a plan?

- What will success look like? How will you know you've achieved your goal?

- How will you prepare for each step?

- How do you plan to motivate yourself when obstacles arise? What are some ways to motivate yourself to get started?

- What do you imagine it would look like if you could accomplish this? 
- What's your next step after today?

- How can you keep yourself on track with this?

It may be helpful for Mary to be given some guidance that would help to manage her anxiety such as:

- To focus on those areas that she can control

- Be aware of picking up on things that have no foundation.

- Talk to someone. Amazingly we can often find that others have had similar experiences.

- Negotiating a contract of work for supervision where these unique experiences can be discussed on a regular basis with an action and support plan in place.

Other questions to use to help guide Mary might include:

- On a scale of 1-10 where 1 means that you have no idea how to manage work at this time and 10 means you are definite about what you need to do at this point in time where would you place yourself on this scale?

- If for example Mary places herself at a 2, you might ask "What is it that is helping you to stay at a 2 ? If you could move to 3 what would you need to do to achieve this? How could other people help you to move a little bit further along the scale? How would you know when you had reached a 3?"

- Have there been other times in your life where you felt unsafe or uncertain and you managed your way through this? What was it that you did that helped you manage this? Were there things that other people did that helped you manage it?

\section{Safe Certainty}

Mason (2019) states that in this domain, there is a desire for certainty to be provided from outside of the self due to a sense of powerlessness and lack of personal agency.

Example: John's manager James has asked him to find new ways of working with service users as he cannot see many service users face to face. He is asked to bring ideas about how he can take his work forward. John has responded by saying "You tell me what I need to do, you're the manager and if you don't know how am I supposed to know?" When James initially came to see me he was very frustrated with John, feeling that there is a desire for certainty - often to be supplied from outside oneself, because when one is in a position of unsafe uncertainty one can lack a sense of personal agency in one's ability to be self - and other - protective. John was not trying enough, did not care and was being difficult. James wanted clear answers from me about what he should do. Instead of rushing to solutions that potentially would have no use anyway, I asked James what other emotions and thoughts might be going on for John. James sat in silence for a minute. I did not interrupt the silence, noticing that James was really trying to pull some thoughts together. When James spoke, his thoughts were that John may be coming from a place of fear. He potentially could be worried about his mum and dad who were shielding at the time. He was potentially worried because his wife's small business was struggling during lockdown. He may feel overwhelmed. He may just want James to provide him with 
answers in trying to achieve safe certainty. There were isomorphic processes (Koltz et al. 2012) at play here.

James felt stuck. At the same time, I had a sense of stuckness, feeling that we were going around in circles during our conversations. I could feel myself being drawn towards a position of safe certainty, paralysis starting to set in. My inner conversation was about a search for movement for myself as well as James. I asked myself what I could do differently, how could I help James to see things through a different lens and enable different possibilities to emerge (use of reflexivity). This enabled me to resist the pull to safe certainty.

I am someone who enjoys using creative and active ways of learning if it connects with the other or others in the room. In my clinical practice I have become more and more intrigued with how physical movement can create paradigm shifts. I tend to use sculpts, physical exercises, physical scaling etc. and have used this with families, frontline staff, and trainee family therapists as a way of navigating situations together. I ask James whether we can carry out an exercise together. I mark out the safe uncertainty framework on the wooden floor with masking tape I keep in the room, placing various pieces of paper on it that mark out the different domains. Looking at the framework I imagine myself hovering above it rather than standing within it, taking a metaposition to the process (figure 2). I also use the Rs discussed earlier, imagining them moving within the domains, opening conversation, that enables the supervisee to consider their position and how they might move within the framework. I place a piece of paper in the middle of the framework asking James what theme he wishes to focus on (figure 2).

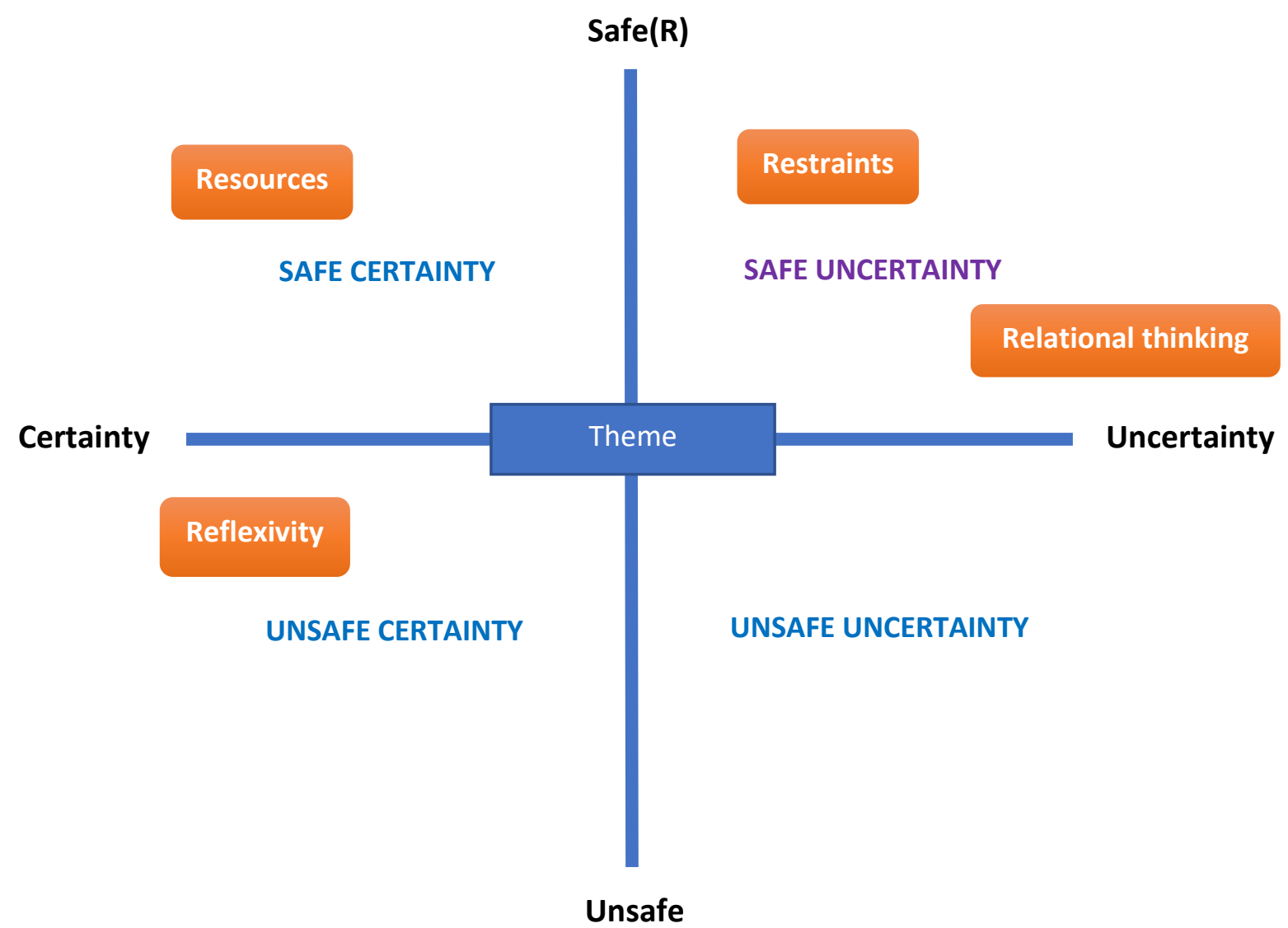

Figure 2. Moving towards safe(r) uncertainty 
He tells me he wants to feel safer in his management of John and wants to help John feel safe and less overwhelmed or frightened. I write this down. I ask James to stand in the safe certainty quadrant and ask him "if you were to stay in this position and I was to give you the answers what would be the benefits and limitations of this?" He begins by saying that at least he would know what to do, then says that this may not help his confidence with John. I ask would he like to stay there or move to a different position. He walks to a position of unsafe uncertainty. A shift has already been created.

I continue to be curious and with the intent of assisting James to come up with his own ideas, ask questions such as

- What have you tried?

- What options do you have?

- What else?

- How possible is each option?

- What do you need more clarity about? What questions can you ask to seek that clarity and who would you ask?

What would it take to bring about change on this issue? I ask James what he has discovered so far. He tells me that he has learned that he had unhelpful conversations with John because he had a fear that things could become confrontational. James had also learned that he needed to language things differently and that he needed to hear about the pressures that were there for John in his personal life.

Attending to gender I asked James whether being a man supervising a man had any impact on how he was viewing the situation. James stated that this might be the case, that he felt both himself and John were trying to be strong individuals that had to show they could deal with anything. James felt that if he were able to show some vulnerabilities himself, that he could enable John to do the same.

As preparation for difficulties that might arise for James I asked:

- What challenges might come our way and how might we meet them?

- What conversation, if begun today, could ripple out in a way that created new possibilities for the future?

By the end of our hour together James had moved himself physically to a position of safe(R) uncertainty. He had hypotheses about what might be going on for John. He had questions that would help him to stay curious in the situation. He had a sense of his own personal agency in being able to support John to manage things differently at work.

\section{Unsafe Certainty}

In this domain life often feels unsafe but the person in this position tends to lean towards feeling convinced of the certainty of their points of view. There is often less curiosity of the other, of the perspectives of other people, and the person in the unsafe certainty position will often try to convince others that their perspective is right (Mason 2019). In this case I may ask whether it is OK to offer some ideas and seek feedback about the staff member's thoughts on these. I have also asked questions such as: 
- Is there anyone who disagrees with what you are saying?

- Are you able to listen to their thoughts or ideas?

- What do you think the other person wants you to hear?

- Can you think of some alternatives? Is there another way to look at it?

- Tell me what you think would happen if you tried doing that?

- What are the pros and cons of this option?

- Which possible pathway do you feel prepared to go down?

I may provide them with options to talk through another perspective while respectfully hearing their views:

- Thanks for helping me understand your side. I can see where you're coming from. My point of view is a bit different...

- Have you ever thought about...?

\section{Some Final Thoughts}

I have made some discoveries for myself while trying to navigate my way through the COVID-19 pandemic especially when helping staff to create possibilities for shifts in practice. Using the safe uncertainty framework, I have a real sense of persistence, actively experimenting, remaining curious, exploring ideas with others, and co-constructing in the room. Managers and supervisors play an important role in enabling staff to come up with new ideas, helping them to identify their own resources and existing strengths. Supervision of supervisors is important as a means to explore ideas, questions, and alternative perspectives to dilemmas and difficulties.

Providing a context for staff to be doubtful is a useful process. The embracing of vulnerability can help frontline and other staff feel stronger as new possibilities emerge and thinking is less constrained by numbers, detail and trying to prove that you can be everything to everybody, particularly during the current pandemic. Using Mason's framework $(1993,2019)$ has made Le Guin's (2017) intolerable uncertainty feel more tolerable, enabling the co-creation of energetic moments, where new possibilities for safe $(R)$ uncertainty emerge and unfold within the supervisory process.

\section{References}

Anderson, Harlene \& Goolishian, Harold (1988) Human Systems, as Linguistic Systems: Preliminary and Evolving Ideas about the Implications for Clinical Theory. Family Process, 27, 371- 393.

Barad, Karen. (2007). Meeting the Universe Halfway: Quantum Physics and the Entanglement of Matter and Meaning. Durham, NC: Duke University Press.

Bateson, Nora (2016) Framing the Symmetry. In: Imelda McCarthy and Gail Simon (Eds.), Systemic Inquiry as Transformative Practice. UK: Everything is Connected Press.

Burnham, John (1992) Approach, Method, Technique. Human Systems, 3, 3-27.

Burnham, John (1993) Systemic Supervision: The Evolution of Reflexivity in the Context of the Supervisory Relationship. Human Systems, 4, 349-381 
Burnham, John (2005) Relational Reflexivity: A Tool for Socially Constructing Therapeutic Relationships. In: Carmel Flaskas, Barry Mason \& Amaryll Perlesz (Eds.), The Space Between. Experience, Context, and the process in the Therapeutic Relationship. UK: Karnac Pubs.

Burnham, John (2012) Developments in Social GRRRAAACCEEESSS: Visible - Invisible and Voiced - Unvoiced. In: Inga-Britt Krause, (ed.) Culture and Reflexivity in Systemic Psychotherapy: Mutual Perspectives (139-160). London: Karnac.

Cecchin, Gianfranco (1987) Hypothesising, Circularity and Neutrality Revisited: An Invitation to Curiosity. Family Process, 26, 405-413.

Deleuze, Gilles \& Guattari, Félix (1988) A Thousand Plateaus: Capitalism and Schizophrenia. London: Athlone Press Ltd.

Goleman, Daniel (1985) Vital Lies, Simple Truths: The Psychology of Self-Deception. New York: Simon \& Schuster.

Hedges, Fran (2010) Reflexivity in Therapeutic Practice. UK: Macmillan Education UK.

Koltz, Rebecca, Odegard, Melissa, Feit, Stephen, Provost, Kent \& Travis Smith (2012) Parallel Process and Isomorphism: A Model for Decision Making in the Supervisory Triad The Family Journal: Counseling and Therapy for Couples and Families 20(3), 233-238

Krause, Inga-Britt (2012) Culture and the Reflexive Subject in Systemic Psychotherapy. In: Culture and Reflexivity in Systemic Psychotherapy. Mutual Perspectives. London: Karnac.

Le Guin, Ursula K. (1969) The Left Hand of Darkness. NYC: Walker and Company.

Mason, Barry (1993) Towards Positions of Safe Uncertainty. Human Systems: The Journal of Systemic Consultation \& Management, 4, 189-200.

Mason, Barry (2005) Relational Risk-taking and the Therapeutic Relationship. In: Carmel Flaskas, Barry Mason \& Amaryll Perlesz (Eds.), The Space Between. Experience, Context and the process in the Therapeutic Relationship. UK: Karnac Pubs.

Mason, Barry (2019). Re-visiting Safe Uncertainty: Six Perspectives for Clinical Practice and the Assessment of Risk. Journal of Family Therapy, 41, 343-356.

Murmurations: Journal of Transformative Systemic Practice Writing Project (2020). http://murmurations.cloud/ojs/index.php/murmurations/writingproject.

Murphy, Francis (ed.) (2004) Walt Whitman. The Complete Poems London: Penguin Books.

Neden, Jeanette \& Burnham, John (2007). Using Relational Reflexivity as a Resource in Teaching Family Therapy. Journal of Family Therapy, 29, 4, 359-363.

Rankine, Claudia (2004) Don't Let Me Be Lonely. An American Lyric. Saint Paul, MN: Graywolf Press.

Roper-Hall, Alison (1998) Working systemically with older people and their families who have 'come to grief'. In: Pauline Sutcliffe, Guinevere Tufnell and Ursula Cornish (Eds.), Working with the Dying and Bereaved: Systemic Approaches to Therapeutic Work, 177-206. London: Macmillan.

Schön, Donald (1983) The Reflective Practitioner: How Professionals Think in Action. London: Temple Smith. Shotter, John (2012). More than Cool Reason: 'Withness Thinking' or 'Systemic Thinking' and 'Thinking about Systems.' International Journal of Collaborative Practices, 3, 1, 1-13. 
Tomm, Karl (1988). Interventive Interviewing: Part III. Intending to Ask Lineal, Circular, Strategic, or Reflexive Questions? Family Process, 27, 1-15.

UK Govt (2020) Guidance: The R Number and Growth Rate in the UK. Accessed $7^{\text {th }}$ September 2020. https://www.gov.uk/guidance/the-r-number-in-the-uk

Wittgenstein, Ludwig (1969) On Certainty. (Anscombe G.E.M., von Wright G.H., eds; Paul D., Anscombe G.E.M., trans). Oxford: Basil Blackwell.

Yeats, William Butler (1994) The Second Coming. In: The Collected Poems of W.B. Yeats. Hertfordshire: Wordsworth Editions Limited.

\section{Author}

Jennifer McKinney is a systemic psychotherapist and supervisor, with a background in social work, currently employed in social care in Northern Ireland, working with children, young people, and families. Jennifer also works in private practice delivering systemic psychotherapy to individuals and families and providing consultation and systemic supervision to organisations. She also provides training in areas such as engagement, relational practice, genograms, and questioning skills. Jennifer is a Clinical Lecturer in Systemic Psychotherapy at Queen's University Belfast and is currently completing her Professional Doctorate in Advanced Research and Systemic Psychotherapy at the Tavistock Clinic. London.

Email: jennmckinney.systemic@gmail.com

\section{Citation}

McKinney, Jennifer (2020). Towards Safe(R) Uncertainty. An Offering for Managers and Supervisors During a

Pandemic. Murmurations: Journal of Transformative Systemic Practice, 3, 1, 113-129.

https://doi.org/10.28963/3.1.17 